\title{
IDENTITAS PRA-INDONESIA DALAM CERITA-CERITA PRA-INDONESIA
}

\author{
Pujiharto, Wening Udasmoro, dan Mutiah Amini \\ FIB Universitas Gadjah Mada \\ email: pujiharto@ugm.ac.id
}

\begin{abstract}
Abstrak
Penelitian ini bertujuan mendeskripsikan karakterisasi tokoh pra-Indonesia dan hubungan antara pola karakterisasi tokoh dengan proses munculnya identitas praIndonesia dalam cerita-cerita pra-Indonesia. Sumber data penelitian adalah cerita berjudul: (1) "Busono" karya Raden Mas Tirto Adhi Soerjo, (2) “Tjerita Si Tjonat" karya F.D.J. Pangemanan, (3) “Tjerita Njai Dasima” karya G. Francis, (4) “Tjerita Njonja Kong Hong Nio" dan (5) "Tjerita Nji Paina" karya H. Kommer. Beberapa konsep yang dipergunakan untuk menjawab permasalahan di atas adalah identitas pra-Indonesia, karakterisasi, dan fokalisasi. Hasil penelitian sebagai berikut. Pertama, tokoh-tokoh dalam cerita-cerita praIndonesia dalam hubungannya dengan identitas pra-Indonesia menunjukkan adanya karakteristik tokoh yang sadar diri dan yang tidak sadar diri. Kedua, penghadiran tokohtokoh dalam cerita-cerita pra-Indonesia dengan karakterisasi yang menujukkan identitas pra-Indonesia memiliki hubungan dengan fokalisasi pengarangnya.
\end{abstract}

Kata kunci: cerita pra-Indonesia, karakterisasi, fokalisasi, identitas pra-Indonesia

\section{PRE-INDONESIAN IDENTITIES IN PRE-INDONESIAN STORIES}

\begin{abstract}
This study aims to describe characterization of pre-Indonesian characters and the relationship between characterization patterns and the process of the appearance of preIndonesian identities in pre-Indonesian stories. The data sources were stories entitled: (1) "Busono" by Raden Mas Tirto Adhi Soerjo, (2) “Tjerita Si Tjonat" by F.D.J. Pangemanan, (3) "Tjerita Njai Dasima" by G. Francis, (4) "Tjerita Njonja Kong Hong Nio" and (5) "Tjerita Nji Paina" by H. Kommer. Several concepts to answer the problems were preIndonesian identities, characterization, and focalization. The findings are as follows. First, characters in pre-Indonesian stories and the relationship with pre-Indonesian identities show that some are self-aware and some are not. Second, the existence of characters in pre-Indonesian stories with characterization shows that pre-Indonesian identities have a relationship with the authors' focalization.
\end{abstract}

Keywords: pre-Indonesian stories, characterization, focalization, pre-Indonesian identities

\section{PENDAHULUAN}

Dalam beberapa dekade terakhir, masyarakat Indonesia dilanda oleh arus globalisasi budaya yang berlangsung sangat masif. Arus globalisasi tersebut ditengarai telah menimbulkan schizofrenia, suatu kondisi keterbelahan jiwa, pada masyarakat (Dewanto, 1991). Hal itu karena globalisasi telah menawarkan sejumlah nilai-nilai sosiokulutral yang saling bertabrakan antara yang satu dengan yang lainnya, suatu kondisi yang oleh para ahli biasa disebut dengan kondisi pascamodern (Steger, 2005). 
Dalam menghadapisituasi yang tidak pasti dan kontradiktif tersebut tentunya masyarakat memerlukan strategi yang tepat sehingga globalisasi, yang menurut para ilmuwan sosial dianggap sebagai hal yang tak mungkin dihindari, bisa memberikan manfaat bagi kemajuan bangsa ini, tidak justru menjadi bencana. Salah satu upaya yang perlu dilakukan untuk menjawab persoalan tersebut adalah dengan berusaha mengenali dan memahami identitas diri masyarakat bersangkutan. Dengan mengenali dan memahami identitas diri, masyarakat Indonesia pun tidak akan mudah goyah dan kehilangan identitas. Untuk itu, pencarian terhadap identitas diri masyarakat Indonesia merupakan tuntutan yang sangat urgen dilakukan.

Salah satu cara untuk melakukan pencarian identitas adalah dengan mengetahui, mengenali, dan memahami budaya masyarakat bersangkutan di masa lalu. Tulisan ini akan membahas salah satu unsur budaya, yaitu karya sastra di masa lalu yang disebut dengan sastra pra-Indonesia, khususnya cerita-ceritanya.

Upaya mengetahui, mengenali, dan memahami sastra pra-Indonesia telah dilakukan oleh para ahli sastra. Faruk lewat buku yang berjudul Belenggu PascaKolonial (2007) telah membahas beberapa cerita pra-Indonesia, yaitu Pangeran Monte Cristo, Gembala Domba, Robinson Crusoe, Max Havelar, Hikayat Kadiroen, dan Sitti Nurbaya dari perspektif pascakolonial. Budianta (2005) juga telah menulis pengantar untuk antologi yang dikumpulkannya dengan kawan-kawannya. Dalam pengantar itu, bahasan Melani berfokus pada ciri-ciri intrinsik cerpen yang disebutnya dengan "kolase multikultural" dalam hubungannya dengan pengarang yang disebutnya sebagai tukang cerita. Dalam pengantarnya itu Melani juga mengkritisi pandangan yang selama ini ada bahwa cerpen Indonesia diawali oleh cerita-cerita M. Kasim pada tahun 1930an. Fakta yang ada, seperti yang terkum- pul dalam antologi itu, cerpen Indonesia telah lahir pada tahun 1870-an. Pandangan Melani ini juga diikuti oleh Mahayana (2006) dan Wahyudi (2000).

Berbicara mengenai identitas pada mulanya seseorang dianggap memiliki given identity. Sementara itu, debat-debat tentang identitas pada zaman sekarang menunjukkan bahwa identitas bukanlah kualitas alami seseorang, melainkan muncul melalui interaksi dengan orang lain dan fokusnya berada pada proses konstruksi identitas (Sarup, 2002: 14). Proses konstruksi ini melibatkan hubungan antara individu dengan kelompok.

Identitas personal adalah bagaimana seseorang memandang diri sendiri dan bagaimana ia dan orang lain terhubung atau bersikap pada diri sendiri. Ketika membentuk identitas personal seseorang akan mencoba menegaskan perbedaan antara satu 'diri' dan 'diri yang lain' sehingga self narration juga terhubung dengan bagaimana mengetengahkan keunikan seorang individu apabila dibandingkan dengan orang lain.

Identitas personal berbeda dengan identitas sosial yang merupakan internalisasi terhadap identifikasi kolektif yang seringkali stereotipikal (Jenkins, 2008: 112). Identitas sosial erat hubungannya dengan keanggotaan terhadap suatu kelompok dan proses identifikasi kolektif. Setiap individu memiliki beragam identitas sosial, di antaranya yang didasarkan pada keanggotaan terhadap kelompok yang penting dan memiliki batasan yang jelas, maupun kelompok dengan batasan yang abstrak dan mungkin ambigu. Seseorang menjadi anggota kelompok karena mengidentifikasi dirinya memiliki kesamaan dengan kelompok tersebut atau perbedaan dengan kelompok yang bukan kelompok tersebut (Jenkins, 2008: 102, 112).

Konsep pra-Indonesia itu sendiri dipahami sebagai babakan waktu sebelum Indonesia sebagai sebuah negara 
terbentuk. Memang kata Indonesia telah digunakan jauh sebelum Indonesia sebagai sebuah bangsa yang merdeka ada. Pada waktu itu, nama itu lebih banyak mengandung pengertian geografis yang samar atau bersifat etnologis semata (Toer, 2003: 20). Indonesia digunakan para sarjana Belanda untuk menunjuk lingkungan geografis yang terdiri atas pulau-pulau, tetapi pulau-pulau itu belum diikat oleh kesamaan tujuan menjadi sebuah bangsa yang merdeka. Malah sebaliknya, di dalam pulau-pulau itu terdapat suku-suku bangsa yang berbeda antara yang satu dengan yang lainnya. Lebih dari sekedar pengertian geografis, bagi Toer (2003: 20), Indonesia dipahami sebagai mempunyai dimensi tertentu, isi tertentu, diakibatkan oleh daya-daya politik dan sosial untuk mencapai kemerdekaan nasional dan berpemerintahan sendiri dengan segala konsekuensinya. Hal itu berarti bahwa Indonesia adalah suatu gagasan yang sedang berada dalam proses pembentukan. Dengan pengertian serupa itu, apa yang dimaksud dengan Indonesia mengacu pada Indonesia yang merdeka pada tahun 1945.

Implikasi dari pandangan di atas adalah bahwa karya-karya sastra yang terbit sebelum tahun 1945 di wilayah yang di kemudian hari disebut dengan Indonesia dikategorikan sebagai sastra pra-Indonesia. Meskipun demikian, sebelum tahun 1945 dimaksud bukanlah menunjuk pada keseluruhannya. Berdasarkan datadata yang ada, bila ditarik mundur ke belakang, hal itu menunjuk pada rentang waktu sampai dengan tahun 1900-an. Dipilihnya tahun tersebut sebagai tahun awal kemunculan didasarkan pada alasan bahwa pada tahun itulah benih-benih antikolonial dalam sastra pada bangsa yang di kemudian hari disebut dengan Indonesia muncul.

Adapun sastra Indonesia adalah sastra yang ditulis dengan bahasa Indonesia pada tahun 1945 dan sesudahnya.
Pertama-tama perlulah dipahami bahwa nama Indonesia dalam konteks tersebut berkenaan dengan keputusan politik, yaitu proklamasi kemerdekaan Republik Indonesia 17 Agustus 1945. Bahwa bahasa Indonesia telah disumpahkan oleh para pemuda pada tahun 1928, itu betul. Namun, pengakuan bahwa bahasa Indonesia adalah bahasa nasional baru diputuskan pada tanggal 17 Agustus 1945, berbarengan dengan dibacakannya proklamasi kemerdekaan Republik Indonesia. Adalah betul juga bahwa sebelum menjadi bahasa Indonesia yang semula adalah bahasa Melayu. Namun, begitu keputusan politik dinyatakan, bahasa Melayu berganti nama menjadi bahasa Indonesia. Apakah dengan demikian bahasa Indonesia sama dengan bahasa Melayu? Jawabnya adalah tidak. Mengapa? Hal itu karena kelahiran bahasa Indonesia tidak bisa dipisahkan dari keputusan politik mengenai pendirian negara Indonesia. Dengan keputusan politik tersebut, Indonesia bukanlah menunjuk pada masa lalu, tetapi menunjuk pada masa depan, sebuah mimpi yang harus diwujudkan. Bahwa Indonesia terkait dengan masa lalu, tentu itu tidak terelakkan. Namun, masa lalu itu tidak harus membebani upaya pembentukan Indonesia yang baru, Indonesia yang modern dan maju. Dengan pemahaman serupa itu, bahasa Indonesia pun bukan lagi dipahami sebagai bahasa Melayu, tetapi sebagai bahasa Indonesia yang dicita-citakan, sebuah mimpi yang harus diwujudkan.

Berdasarkan uraian di atas, apa yang disebut dengan sastra pra-Indonesia adalah sastra yang mengandung benih-benih kesadaran antikolonial yang terentang dari tahun 1900-an sampai dengan tanggal 17 Agustus 1945 yang semangat tersebut di kemudian hari menjadi dasar pembentukan Negara Kesatuan Republik Indonesia. Seperti telah dikemukakan sebelumnya, penentuan tahun 1900-an sebagai tahun awal didasarkan pada kenyataan bahwa 
pada tahun itulah benih-benih kesadaran antikolonial muncul pada bangsa ini.

Selanjutnya, istilah karakterisasi berasal dari kata characterization yang dalam bahasa Indonesia biasa diterjemahkan menjadi penokohan atau perwatakan. Dua istilah dalam bahasa Indonesia tersebut memiliki arti yang berbeda: penokohan lebih berhubungan dengan tokoh, lebih dekat pada penggambaran fisik, sedangkan perwatakan lebih berhubungan dengan watak, sifat-sifat yang melekat padanya. Dalam penelitian ini, pengertian istilah karakterisasi lebih dekat pada pengertian perwatakan. Yang dimaksud adalah penggambaran pengarang mengenai karakter tokoh (Luxemburg, 1989: 131). Karakter adalah sikap, ketertarikan, keinginan, emosi, dan prinsip moral yang dimiliki tokoh (Stanton (1965: 17). Pengertian karakter yang demikian bukanlah dipahami semata-mata bersifat fiktif dan imajinatif, tetapi dipahami sebagai cerminan dari kondisi sosial budaya masyarakatnya. Kondisi dimaksud mengacu pada kondisi sosio historis yang konkret, yaitu kehidupan masyarakat yang berlangsung di era pra-Indonesia.

Karakterisasi seperti terurai di atas tidak bisa dilepaskan fokalisasi pengarang. Yang dimaksudkannya adalah posisi pusat kesadaran pengarang di dalam menyajikan fakta-fakta imajinatif (Luxemburg, 1989: 131-137). Sebagai salah satu sarana cerita, sudut pandang tertentu dipilih oleh pengarang karena pengarang memiliki tujuan untuk mendapatkan pengalaman artistik. Dalam penelitian ini, penggunaan konsep sudut pandang dimaksudkan untuk mengeksplorasi identitas kepraindonesiaan. Karena pengarang-pengarang sastra pra-Indonesia tidak semuanya orang pribumi, belum tentu fokalisasinya dalam bercerita berkenaan dengan identitas kepraindonesiaan, tetapi bisa jadi justru hal-hal yang bertolak belakang dengannya.

\section{METODE}

Sumber data penelitian adalah beberapa cerita pra-Indonesia, yaitu: (1) "Busono" karya Raden Mas Tirto Adhi Soerjo, (2) "Tjerita Si Tjonat" karya F.D.J. Pangemanan, (3) "Tjerita Njai Dasima" karya G. Francis, (4) "Tjerita Njonja Kong Hong Nio" dan (5) "Tjerita Nji Paina" karya H. Kommer. Langkah-langkah yang dilakukan dalam penelitian ini adalah sebagai berikut. Pertama, melakukan pembacaan secara berulang-ulang terhadap cerita-cerita pra-Indonesia yang dijadikan fokus bahasan. Kedua, mengidentifikasi karakteristik cerita-cerita tersebut, khususnya berkenaan dengan tokoh-tokoh yang dicitrakan sebagai orang-orang pribumi. Dalam melakukan pengidentifikasian, klasifikasi dilakukan dengan mendasarkan pada predikat yang melekat pada tokoh seperti tergambar dalam cerita. Ketiga, melihat hubungan antara karakteristik cerita dengan identitas kepraindonesiaannya. Berkenaan dengan langkah ketiga ini, karakteristik tokoh diklasifikasikan berdasarkan tingkat kesadarannya: tokoh yang sadar diri dan tokoh yang tidak sadar diri.

\section{HASIL DAN PEMBAHASAN Karakteristik Tokoh Berdasarkan Ting- kat Kesadarannya}

Gambaran mengenai kehidupan sosial budaya di era pra-Indonesia sangat diwarnai oleh karakteristiknya sebagai sebuah bangsa yang terkolonisasi (colonized). Hal itu tampak dalam pencitraan tokoh-tokoh dalam cerita-cerita pra-Indonesia. Tokohtokoh cerita di dalamnya sebagiannya digambarkan sebagai orang-orang yang tak berdaya dalam menghadapi kolonisasi meskipun mereka adalah orang-orang yang sadar diri. Bahkan ada yang ditampilkan sebagai orang-orang yang bukan hanya tak berdaya tetapi bahkan juga tidak sadar diri dan libidinal (semata-mata hanya mencukupi kebutuhan libido). 


\section{Tokoh-Tokoh Yang Sadar Diri}

Yang dimaksud dengan tokoh yang sadar diri adalah tokoh yang mampu melakukan refleksi diri (self reflection). Berdasarkan refleksi dirinya itu ia melakukan tindakan tertentu yang dipandang paling baik dan mampu membuat dirinya mengalami keseimbangan diri. Beberapa tokoh yang merepresentasikan karakteristik yang demikian adalah Busono, $\mathrm{Nji}$ Paina, dan Albaram.

Busono, seorang yang bekerja sebagai wartawan pada sebuah surat kabar Melayu milik orang Belanda, dulunya pernah kuliah di sekolah dokter. Meskipun tidak sempat lulus dari sekolah dokter, bukan berarti Busono orang yang bodoh. Busono masih terbiasa berkumpul dengan temantemannya di sekolah dokter tersebut seperti Sembodo dan Waryo. Perbincangan dengan teman-temannya di sekolah dokter menggambarkan bahwa dirinya adalah salah satu kaum terdidik yang memiliki kepedulian terhadap persoalan orang pribumi, kritis terhadap kebijakan pendidikan Pemerintah Belanda. Karena keadaan yang serba terbatas, dan bahkan juga keadaan sebagian orang pribumi yang bermental korup, mereka belum bisa mewujudkan harapan-harapannya secara maksimal. Lewat kerja jurnalistiknya, Busono ingin berbuat yang terbaik bagi bangsanya, ingin memberikan penyadaran pada bangsanya agar menjadi bangsa yang maju. Ia tidak mau mengisi koran hanya dengan kabar-kabar guntingan atau salinan dari Belanda.

- ... selama redaktur koran Melayu masih mau mengisi korannya dengan kabar-kabar guntingan atau salinan dari koran-koran Belanda, yang tak bernilai atau penuh dengan karangan Dadap dan Waru, yang belum tahu etika pers, koran kita tetap tak bernilai. Pers adalah matahari bagi dunia maka kita mesti mengerti bahwa pers Melayu bisa tumbuh seperti cendawan di musim hujan, tapi segera berontokan bagaikan daun layu. Aku sendiri ingin sekali merombak keadaan semacam ini. Koranku akan aku isi dengan pikiranku dan pikiran orang-orang cerdik pandai, yang bisa mendidik bangsanya ke medan kemajuan dan kesempurnaan. Menurut pendapatku aku merasa belum cukup dengan pengetahuan yang pernah aku peroleh dari sekolah rendah sampai sekolah dokter (Soerjo, 1985:375).

Busono juga memiliki pandangan mengenai pentingnya memperjuangkan harkat dan martabat manusia tanpa memandang asal bangsa. Tidak seperti pandangan kebanyakan orang, bagi Busono, posisi seorang nyai Belanda tidaklah rendah. Nyai Belanda tak beda dengan para selir raja. Meskipun bila sudah tidak lagi dibutuhkan nyai bisa disingkirkan oleh tuannya, tetapi kalau punya anak, anaknya itu akan tetap dipungut oleh tuannya dan mendapat perlakuan yang baik dan bisa mendapat kedudukan sebagaimana anakanak selir raja yang bisa menjadi bupati atau memiliki kedudukan yang lain. Oleh karena itu, Busono berpendapat bahwa tidaklah tepat bila dikatakan bahwa selir itu berkedudukan tinggi dan dihormati oleh masyarakat, sedangkan nyai tidak. Hal itu karena anak-anak yang dilahirkannya, sebagai keturunan bangsa kulit putih, tetap memiliki kedudukan yang diperhitungkan dalam masyarakat.

Selama bangsa saya sendiri masih suka memelihara selir atau belum mau menikahi, jika belum bunting, selama di antara bangsawan-bangsawan masih banyak yang anak jadah, selama ada anak Sunan yang ditolak menjadi imam, selama masih ada segala ini tak adillah kalau orang masih menghina nyai-nyai, yang menghambakan diri pada orang Belanda atau bangsa lain. Toh anak mereka sempat mendapat pelajaran baik, berkedudukan baik, dan bisa bekerja dengan baik, tapi tak beda dari anak jadah bangsawan, 
yang bisa jadi bupati atau raden ayu. (Soerjo, 1985: 386)

Dengan dasar pandangan yang serupa itu, Siti Ningrum, seorang nyai Belanda yang Busono kenal dekat dengannya, disarankan agar memiliki anak dari tuannya. Dengan cara demikian, Siti Ningrum akan mendapatkan keturunan yang akan dipandang baik oleh masyarakat. Bila tidak, sebaiknya Siti Ningrum minta pisah saja dan kemudian mencari laki-laki yang mau menikahinya dengan baik-baik.

Selain itu, Busono juga digambarkan sebagai orang yang bersikap kritis terhadap budaya feodal yang hidup di masyarakat. Ketika ditawari untuk menikah dengan anak seorang bupati oleh Raden Noto, Raden Noto mengemukakan bahwa bila Busono menikah dengan anak bupati, akan mudah bagi Busono mengembangkan karirnya di birokrasi karena mertuanya nanti memiliki kekuasaan. Bagi Busono, kenyataan yang seperti itu dipandang menghambat kemajuan bangsa.

- Ya-ya saya percaya. Tapi dengan demikian pamanda berarti mengajak saya buat mundur selangkah. Hidup dengan gaya kuno. Maksud saya cari nama dan kehormatan. Atau makan dengan rangkak-rangkak menaiki tangga priyayi? Atau lebih lazim dikatakan: mengejar-ngejar kancing Willem. Apakah pamanda kurang percaya, bahwa di luar dunia priyayi kita masih bisa hidup senang dan wajar? Ya-Ya, saya tahu bahwa sesuai dengan kebangsawanan saya dengan mudah sekali bisa jadi juru tulis. Tak seberapa lama saya pasti naik jadi asisten wedana, kemudian diangkat jadi wedana. Kelak saya akan terangkat juga jadi bupati. Sungguh akan menjadi lebih sia-sialah nasib kita anak negeri. Tak mungkin kita kan menjadi satu bangsa yang bisa memakmurkan kembali tanah kita se- perti dulu nenek-moyang kita pernah jaya. Belum satu tahun saya bekerja, tapi gaji sudah menyamai seorang wedana. Saya lebih bebas dan lepas dari wedana yang harus melayani beberapa pembesar yang sering berlainan pendapat dan perintahnya. Dalam melayani mereka dia harus pandai bermain sulap. Siapa bisa menyangkal, bahwa zonder jadi priyayi pun saya bisa hidup senang bersama anak dan istri? (Soerjo, 1985: 395)

Tokoh yang sadar diri akan ketertindasannya dan kemudian melakukan perlawanan terhadap yang menindas dan perlawanannya itu berhasil adalah $\mathrm{Nji}$ Paina. Nji Paina adalah anak dari seorang pribumi Jawa bernama Niti Atmodjo, yang bekerja sebagai juru tulis pabrik gula. Nji Paina akan dijadikan nyai oleh atasan ayahnya yang bernama Briot. Karena sikap Briot yang kasar, yang pikirannya "hanja botol sopi (minuman keras) dan prampoean elok" (h. 382), yang bahkan karena bunyi ucapannya yang jelek lalu ia dipanggil "tjeleng-tjeleng", Nji Paina, meskipun suaminya sudah meninggal karena diserang penyakit cacar, tetap berusaha menolak. Namun, setelah mengetahui bahwa ayahnya harus mengembalikan uang dalam jumlah besar karena dalam menjalankan tugasnya sebagai kuli kecil seringkali uangnya hilang karena dicuri para kuli dan bila tidak bisa mengembalikan ia akan dipecat, akhirnya dengan sangat berat hati Nji Paina bersedia dijadikan nyainya Briot.

Dalam keadaan yang sangat terpojok itu, Nji Paina berpikir keras: cara apa yang bisa dilakukan untuk bisa menghindar dari, sekaligus melawan, Briot. Rupanya, pada siang hari sebelum malamnya Nji Paina harus datang ke rumah Briot untuk menjadi nyainya, datang musim cacar yang mematikan. Nji Paina, yang sesungguhnya tidak sudi menjadi nyainya Briot, kemudian datang ke orang-orang yang 
terkena cacar dan kemudian menciuminya dengan tujuan mau menularkannya ke Briot supaya Briot celaka. Karena itu, begitu sampai di rumah Briot pada malam harinya, Nji Paina langsung menciumnya dengan tujuan menularkan penyakit cacar itu secepatnya. Upaya itu berhasil dan mampu membuat Briot sakit keras dan beberapa hari kemudian mati.

Adapoen Nji Paina soedah ambil satoe kepoetoesan. Sering kali ia dapet dengar dari ajahnja dan dari orangorang lain kaloe satoe orang iang waras dateng bertjampoer orang pada iang sakit tjatjar, penjakit itoe nanti mendjangkit dan menoelar padanja. Penjakit itoe gampang di pindahken dari satoe ka lain orang. Maka Nji Paina soedah tetapken atinja aken bikin mati toean Briot dengan djalan iang sedemikian.

Bahoea di kampoengnja Nji Paina ada bebrapa orang, iang dapet penjakit tjatjar amat kerasnja. Di itoe hari Nji Paina pergi meliat semoea orang, iang sakit tjatjar itoe.

Anak-anak iang sakit tjatjar sambil menarik napas ia pegang dan tjioem moeka moekanja iang amat roesak, sebelonnja ia pergi di roemahnja toean Briot, ia pergi bertemoeken satoe orang prampoean, iang djoega ada penjakit tjatjar amat sangetnja, dan prampoean ini di tjioemnja bebrapa kali. Kemoedian Nji Paina berangkat keroemah toean Briot, iang memang soedah toenggoe datengnja dengen tiada sabaran. Koetika ia lihat Nji Paina dari djaoeh, ia sigrah hampirken padanja, teroes pelok dan tjioem $\mathrm{Nji}$ Paina, iang amat tjantik dan elok itoe. Sagenap hari Nji Paina moesti doedoek di pangkoenja toean Briot dan tiada brentinja ia ditjioemi oleh toean itoe.

Hata maka sepoeloeh hari kemoedian, toean Briot kena penjakit tjatjar amat sangetnja. Bagimana djoega di obatin, toean Briot tiada djadi semboeh, maka ampat hari kamoedian, orang dapetin toean Briot mati terletak di atas oebin di depan roemahnja dan roepanja seperti ia soedah menanggoeng sangsara besar selama sakitnja itoe. (Kommer dalam Toer, 2003: 390-391)

Yang juga terkategori tokoh yang sadar diri adalah Albaram, tokoh dalam “Tjerita Njonja Kong Hong Nio", seorang lelaki yang masih keturunan dari keluarga Kerajaan Banten. Karena kerajaan itu dihancurkan oleh Daendels, Albaram pun tidak bisa menikmati hidup enak di kerajaan. Ia bekerja sebisa dan seadanya hingga kemudian bekerja pada seorang Cina yang kaya raya bernama Liem Tek Kan. Dalam usia yang sudah tua, Liem Tek Kan yang sudah beranak tiga dari istrinya yang dulu, menikah lagi dengan Kong Hong Nio, seorang janda beranak satu. Dalam waktu yang tidak lama setelah pernikahannya, Liem Tek Kan meninggal. Akhirnya, harta kekayaan peninggalan Liem Tek Kan dikelola oleh Kong Hong Nio untuk terus dikembangkan dan secara pelan-pelan harta yang diwasiatkan untuk tiga anak Liem Tek Kan akan diberikan bila telah tiba waktunya. Setelah kematian Liem Tek Kan, Albaram pun kemudian menjadi pekerjanya Kong Hong Nio. Dalam keadaan serupa itu, Albaram pun ingin kembali seperti dulu ketika kerajaan Banten masih berjaya: kebutuhan materialnya tercukupi. Caranya adalah dengan merayu Kong Hong Nio, menyatakan cinta padanya dan akan menikahinya, tetapi yang sesungguhnya diinginkannya adalah harta kekayaan peninggalan Liem Tek Kan yang sekarang dikelola oleh Kong Hong Nio.

Hatta maka lantaran karadjaan Bantam di bikin binasa banjak orangorang bangsawan toeroenan Sultan mendjadi miskin dan melarat, achirnja marika ini tersiar di sini sana, terpaksa moesti tjari penghidoepan dengan 
berkoeli di kebon. Bermoela marika ini dapet banjak toloengan dari orangorang ketjil, akan tetapi lama kelamahan tiada di endahken lagi. Maka seboleh bolehnja ia orang masih maoe dapet kombali kabesarannja, hingga di sini sana marika itoe bikin hoeroe hara itoe, lawan pada compenie. Maka oleh telitih dan radjinnja pemerentah di waktoe itoe, beroentoenglah hoeroe hara itoe tiada sampei kadjadian.

Seperti ada ditjeritaken oleh iang mengarang hikajat ini maka kabanjakan antara orang orang bangsawan itoe suedah trepaksa djadi perampok.

Sjahdan maka Mas Albaram, tjoetaknja toean tanah Kong Hong Nio, djoega ada asal toeroenannja orang bangsawan di Bantam, dan sebagai iang lain lain ia telah djadi begitoe miskin hingga ia soedah terpaksa tjari kerdjaan di bilangan Betawi, dan achirnja soedah djadi tjotaknja toean tanah di Babakan, Liem Tek Kan. (Kommer dalam Toer, 2003:327-328)

Karena bisa membaca akal bulus Albaram, Kong Hong Nio tidak menanggapi maunya Albaram. Sakit hati terhadap sikap Kong Hong Nio, Albaram pun berusaha membalas dendam terhadapnya. Adapun cara yang dilakukannya adalah dengan menghasut tiga anak Liem Tek Kan agar melakukan aksi pembunuhan terhadap Kim Nio, anak Kong Hong Nio dengan suaminya yang dulu. Namun, upaya Albaram tersebut tidak mendapatkan hasil. Pada akhir cerita dikisahkan karena ketahuan telah berupaya melakukan pembunuhan, Albaram dihukum gantung.

\section{Tokoh-Tokoh Yang Tidak Sadar Diri}

Yang dimaksud dengan tokoh yang tidak sadar diri adalah tokoh-tokoh yang dalam aktivitasnya hanya mengikuti naluri hewaniyahnya seperti kebutuhan makan, minum, dan pemenuhan kebutu- han seksualitas. Dalam cerita-cerita praIndonesia tokoh yang demikian tampak pada para nyai, para perampok, dan para dukun. Kisah tentang nyai ini muncul pada "Busono" dan"Tjerita Njai Dasima. Dalam "Busono" dikisahkan tentang Siti Ningrum, yang dijadikan nyai oleh dokter Solern. Karena tidak memiliki kemampuan refleksi diri, Siti Ningrum mau menjadi nyai. Kehidupan Nyai Ningrum tidak dikisahkan oleh dirinya, tetapi lewat perbincangannya dengan Busono. Menurut penangkapan Busono terhadap desas-desus yang berkembang di masyarakat, Ningrum sebagai nyainya dokter Solern dikenal "hanya main eret harta dan duit semata-mata" (Soerjo dalam Toer, 2003: 386). Dokter Solern mau memberi uang dan harta yang cukup karena Ningrum masih muda, masih cantik. Dengan keadaan yang serupa itu, Busono pun memberikan penyadaran padanya. Dikatakan padanya bahwa bila sudah tua nanti, seperti nyai-nyai yang lain, Ningrum akan ditinggalkan tuannya. Karena itu, Busono mengingatkan pada Ningrum agar bisa mendapatkan anak dari tuannya. Bila punya anak dari tuannya, yang nantinya akan dirawat dan disekolahkan di Eropa, tentulah Ningrum akan lebih dihargai dan lebih terhormat. Mendengar nasihat Busono yang demikian Siti Ningrum tidak bisa berbuat apa-apa kecuali menangis, bahkan di saat lain dia langsung jatuh sakit.

“Tjerita Nyai Dasima" yang ditulis oleh G. Francis mengisahkan kehidupan Dasima yang dijadikan nyai oleh seorang berkebangsaan Inggris bernama Edward W. Sebagai seorang nyai, Dasima hidup bersama dengan Edward W. tanpa ikatan pernikahan. Meskipun demikian, kehidupan bersama keduanya diliputi rasa cinta dan kasih. Dasima memiliki beberapa budak di rumahnya. Saking cintanya Edward W. pada Dasima, Edward W. tidak merasa berat hati memberikan harta (uang dan barang) dan berbagai hal 
yang disenangi Dasima. Bahkan sempat terpikir kalau Dasima memeluk agama Kristen, Edward W. akan menikahinya. Dari hubungan itu, lahir seorang gadis bernama Nanci.

Dengan keadaan yang serupa itu, Dasima menjadi terkenal di kampungkampung Islam. Keadaan Dasima yang seperti itu telah menimbulkan rasa ingin memiliki pada banyak lelaki untuk bisa mendapatkan hartanya. Karena bujukan yang dilakukan oleh banyak orang tidak membuahkan hasil, salah seorang lelaki muda di Pedjambon yang bernama Samioen mencoba mengakalinya. Karena bertujuan supaya menjadi kaya, niat Samioen tersebut mendapat dukungan istrinya. Untuk mewujudkan niatnya itu, Samioen minta tolong pada Ma Boejoeng dengan mengelabuinya bahwa niatnya itu adalah untuk menyelamatkan Dasima dari kekafiran karena Dasima telah dijadikan njai oleh orang Kristen. Mendengar permintaan Samioen itu, apalagi tindakannya itu adalah satu bentuk amal kepada Nabi Muhammad, Ma Boejoeng dengan senang hati menjalankannya.

Ma Boejoeng pun datang ke rumah Dasima dengan mengaku sebagai orang miskin dan ia berniat bekerja di tempat Dasima. Karena kasihan pada Ma Boejoeng, Dasima pun dengan persetujuan Edward W. menerimanya untuk bekerja meskipun Tuan Edward W. pada mulanya menolaknya karena Ma Boejoeng dipandang sudah tua yang tentunya tidak produktif lagi. Setelah beberapa lama bekerja di tempat Dasima, pelan-pelan Ma Boejoeng mulai mewujudkan niatnya Samioen. Mula-mula Ma Boejoeng bertanya pada Dasima apakah ia masih meyakini Islam sebagai agamanya. Nyai Dasima jawab, "Ya". Selanjutnya Ma Boejoeng pun mengeluarkan jurus-jurusnya: menyadarkan Nyai Dasima kalau masih beragama Islam tentunya harus mengikuti aturan agama Islam, seperti melakukan sembahyang, bersedekah serta bertobat dari kekafiran. Sembari itu, Ma Boejoeng mengumpulkan rambut yang diminta oleh Samioen atas perintah Haji Salihoen untuk dijadikan sarana untuk memisahkan cinta kasih Dasima dengan tuannya. Karena upaya dengan cara itu tidak berhasil, Samioen pun mencari cara lain, yaitu dengan menyuruh Saleha ibunya dan Hajati istrinya (yang sebelumnya sudah dinasihati oleh Haji Salihoen supaya mereka mendukung niat Samioen agar bisa mendapatkan kekayaan dari Dasima) untuk datang ke rumahnya Dasima di saat Tuan Edward tidak ada dan pada saat itulah mertua dan istrinya memengaruhi Dasima dengan berbagai cara agar niat Samioen bisa terwujud. Suatu saat, beberapa hari setelah Dasima berkunjung ke rumah Samioen untuk menghadiri syukuran, Ma Boejong mengatakan bahwa Samioen ingin membebaskan Dasima dari kekafiran dan neraka dan mengajaknya masuk surga dengan cara menikahinya. Mendengar tawaran Ma Boejoeng, Dasima pun terpengaruh dan kemudian menyanggupinya. Malamnya, Dasima pun mengatakan pada Tuan Edward bahwa dirinya minta pisah dan mengatakan bahwa seluruh harta yang sudah diberikan oleh Edward akan dibawa. Mendengar permintaan Dasima Edward kaget karena selama ini ia merasa tidak ada masalah tetapi tiba-tiba Dasima minta pisah. Karena Dasima memaksa untuk berpisah, Edward pun akhirnya mencari notaris untuk menyelesaikan soal harta tersebut.

Setelah urusan notaris itu beres, Dasima pun meninggalkan rumah Edward. Dengan ditemani Ma Boejoeng, Dasima menuju rumah Samioen dan kemudian dinikahi oleh Samioen. Setelah menjadi istri Samioen, Samioen pun mengaturatur Dasima agar mengenakan pakaian yang sesuai dengan ajaran Islam, melepas perhiasan, dan menyerahkan seluruh kekayaannya pada Samioen karena menurut ajaran Islam lelakilah yang mengatur 
perempuan. Lama-kelamaan, Hajati istri Samioen pun mulai bersikap kasar terhadap Dasima hingga akhirnya Dasima pun berniat minta pisah dari Samioen dan berniat kembali ke desanya. Daripada menimbulkan citra yang tidak baik, Samioen berniat membunuh Dasima. Untuk mewujudkan niatnya itu, Samioen menskenario sedemikian rupa: meminta kepada Hajati istrinya agar berbaik-baik dengan Dasima dan menghubungi Poasa, seorang pembunuh untuk melakukan pengaturan sedemikian rupa agar pembunuhan bisa dilakukan. Rencana pembunuhan bisa dilakukan dan kemudian mayat Dasima dibuang di kali. Namun, ternyata mayat Dasima tersangkut di dekat rumahnya Edward. Edward pun melapor pada polisi, dan setelah dicermati, diketahui ternyata mayat itu adalah mayat Dasima. Polisi berusaha mengusut siapa pelakunya dan menangkap Samioen dan Poasa untuk diberi hukuman yang setimpal.

Selain para nyai, yang juga bisa dikategorikan sebagai tokoh yang tidak sadar diri, dan bahkan libidinal, adalah mereka yang menjadi perampok. Tokoh perampok ini tergambar dalam cerita "Si Tjonat". Diceritakan bahwa Tjonat adalah anak seorang kepala desa yang sejak kecil sudah suka main top dan uang yang digunakan untuk main itu adalah hasil penjualan barang-barang atau hewan $\mathrm{cu}$ rian. Apabila ada orang yang lapor pada ayahnya bahwa Tjonat mencuri, ayahnya tidak percaya. Suatu saat ayahnya mendapati Tjonat melakukan tindakan jahat dan kemudian memarahi Tjonat dengan pukulan yang keras. Akibat dari kemarahan ayahnya itu, Tjonat kemudian minggat. Sebelum minggat untuk selamanya itu, terlebih dahulu Tjonat membunuh Si Bohong, seorang anak yang sedang dalam perjalanan pulang bersama-sama dengan kerbau piaraannya dan merampok salah satu kerbau terbesarnya. Dengan membawa kerbau rampokannya itu Tjonat kemudian menemui Gondit, temannya main top. Bersama Gondit inilah hasil rampokannya dibawa ke pasar yang jauh dari tempat tempat keduanya. Setelah mendekati pasar, Tjonat bersembunyi di suatu tempat dan Gondit berangkat ke pasar untuk menjual kerbaunya itu. Setelah kerbau terjual, Gondit tidak menceritakan laku berapa kerbau jualannya. Setelah Tjonat bertanya, baru Gondit mengaku bahwa kerbaunya laku lima belas rupiah. Ketika Tjonat minta sebagiannya, Gondit tak memberikannya dengan mengatakan akan menyimpankannya lebih dulu. Tjonat pun jadi curiga dengan sikap Gondhit yang seperti itu, dan dia juga curiga bahwa Gondit telah berdusta tentang harga jual kerbau dan memang benar kerbaunya telah laku dua puluh lima rupiah. Akhirnya, perkelahian pun tak terhindarkan dan Si Tjonat berhasil membunuh Gondit. Setelah itu, Tjonat pun berlari ke hutan dan kemudian ia habiskan uang hasil penjualan kerbaunya itu untuk main top. Setelah uang habis, Tjonat pun bekerja dari satu tempat ke tempat lain seadanya hingga suatu ketika ia diterima bekerja pada seorang Belanda bernama Tuan Opmeijer. Karena tuannya tidak suka dengan Tjonat digantilah namanya dengan Jonas.

Setelah Jonas bekerja cukup lama pada tuannya itu, rupanya Tuan Opmeijer menerima seorang pekerja baru, yaitu Njai Saipa untuk bekerja di tempatnya. Njai Saipa ini kemudian jadi orang kepercayaan Tuan Opmeijer. Banyak pekerjaan yang dulu dikerjakan Jonas kini diserahkan pada Njai Saipa. Bahkan Njai Saipa pun kemudian berani menyuruh-nyuruh Jonas. Karena Saipa memang cantik, selain ada rasa benci tersaingi, Tjonat juga tertarik pada Saipa. Dengan perasaan yang demikian itu, Tjonat kemudian mengajak Saipa untuk meninggalkan rumah Tuan Opmeijer dengan membawa seluruh kekayaan Tuan Opmeijer yang bisa dibawa dan berniat akan menikahinya. Karena 
takut, Saipa pun tidak bisa menolak tawaran itu. Ketika waktu yang tepat telah datang, yaitu ketika Tuan Opmeijer berpesta dengan teman-temannya sehingga pikirannya terkonsentrasi pada pesta itu, Tjonat dan Saipa menjalankan aksinya. Kekayaan Tuan Opmeijer yang sudah dipersiapkan dibawa pergi oleh keduanya dengan menyewa sebuah perahu menuju rumahnya Saipa. Ketika mendapati Saipa pulang bersama Tjonat, ayah Saipa, Kaenoen, semula menerimanya dengan benci. Namun, karena Tjonat membawa uang banyak, Kaenoen kemudian menerima Tjonat dengan senang hati. Seperti janjinya dulu, Tjonat pun kemudian membelikan kerbau dan sawah. Namun, setelah kekayaan Tuan Opmeijer yang dibawanya habis, Tjonat yang tidak punya pekerjaan itu tidak punya penghasilan lagi. Dari perkawinannya dengan Saipa lahir seorang anak, tetapi dalam beberapa hari kemudian mati.

Sejak itu, Tjonat sering tidak di rumah dan biasa berkumpul dengan para penjahat untuk menghisap candu dan main top. Kalau tidak punya uang, Tjonat merampok. Tjonat pun menjadi terkenal dan tinggalnya berpindah-pindah dari hutan yang satu ke hutan yang lain. Karena sudah lama Tjonat tidak pulang, Saipa, menurut keyakinannya, boleh menerima lamaran lelaki lain. Rupanya, niat Saipa terdengar oleh Tjonat. Tjonat pun marah besar. Akhirnya, Tjonat berniat menemui pulang untuk menemui Saipa. Di tengah jalan, Tjonat mendapati Kaenun, ayah Saipa, turut terlibat dalam huru-hara dan kemudian ditangkap polisi. Hal itu membuat Tjonat merasa senang karena tak ada yang bakal menghalangi langkahnya. Sesampai di rumah Saipa, Tjonat pun kemudian dengan kejam membunuh Saipa.

Suatu saat, Tjonat dan kawan-kawannya mengamati rumah sebuah keluarga Cina, yaitu Baba Lie A Tjip, yang dari luar tampak kaya. Namun, rupanya, ketika akan merampok barang-barang milik keluarga Cina itu, ia mendapati di luar rumah itu seorang gadis cantik anak pemilik rumah itu yang bernama Lie Gouw Nio. Tjonat tertarik pada gadis itu dan membatalkan niatnya merampok. Untuk itu, pada suatu saat Tjonat minta tolong dua temannya untuk mencuri Lie Gouw Nio. Ketika Lie Gouw Nio sudah berhasil dibawa, di tengah jalan dua teman Tjonat yang membawa Lie itu menghisap candu terlebih dahulu hingga terlupa. Pada saat itulah Lie memanfaatkan kesempatan itu untuk melarikan diri dan akhirnya bisa pulang sampai rumah. Setelah tersadar, kawannya kaget karena Lie sudah tidak ada lagi. Mereka kemudian membuat laporan palsu hingga Tjonat dan kawan-kawannya itu kemudian berniat merampok kekayaan Baba Lie A Tjip. Ketika tahun Tjonat dan kawan-kawannya datang, Baba Lie A Tjip, istri, saudaranya yang kebetulan ada di rumah itu, dan Lie Gouw Nio keluar dari rumah itu dan bersembunyi di kandang babi. Setelah dimasuki ternyata di dalam rumah itu tidak ada orang dan juga tidak ada barang-barang yang bisa dirampok, Tjonat dan kawan-kawan pun melempar obor apinya ke atap rumah itu dengan harapan terbakar. Namun, obor itu bisa diambil oleh saudaranya Baba Lie A Tjip hingga rumah itu tak sempat terbakar.

Kegagalan mendapatkan Lie Gouw Nio membuat Tjonat kalap. Berbagai macam cara dilakukannya untuk bisa mendapatkan Lie Gouw Nio. Kali ini Tjonat tidak lagi berniat merampok, tetapi hanya ingin mendapatkan Lie Gouw Nio. Untuk mewujudkan niatnya itu, Tjonat minta tolong Si Basman. Dengan melakukan penyamaran, Si Basman bisa melakukan muslihat dengan cerdik hingga akhirnya Basman yang sesungguhnya adalah orangnya Tjonat justru dimintai bantuan untuk pengamanan perjalanan sejumlah 20 orang untuk mengiringi Baba Tio Lok Ho, istrinya dan Lie Gouw Nio menuju 
Tangerang. Di tengah perjalanan, karena semua pasukan pengamanan memang orangnya Tjonat, dengan gampang Tjonat menculik Lie Gouw Nio, dan membawanya ke persembunyiannya di tengah hutan. Sementara itu, Baba Tio Lok Hio dan istrinya terus melanjutkan perjalanan dan sesampainya di tempat tujuan mereka langsung menyampaikan penculikan pada Tio Sing Sang, tunangan Lie Gouw Nio. Mendengar kabar itu, Tio Sing Sang, yang memang sudah mempersiapkan diri dengan berbagai latihan fisik, dan bahkan sudah dengan meminta ijin pejabat setempat, untuk menghabisi Tjonat, langsung memburu Tjonat. Karena Tio Sing Sang memang sudah mendengar wilayah persembunyian Tjonat, dengan cepat ia menemukan keberadaan Tjonat. Setelah saling beradu muka terjadilah perkelahian di antara mereka. Ketika Tjonat melarikan diri dengan membawa Lie Gouw Nio dengan menyeberangi sungai, Lie Gouw Nio sempat tertusuk pisaunya Tjonat hingga terjatuh di sungai. Namun, ketika Tjonat berusaha melarikan diri lebih jauh, pasukan yang telah disiapkan oleh pejabat setempat bisa mengepung Tjonat, dan akhirnya Tjonat bisa ditangkap dan kemudian dihukum gantung. Lie Gouw Nio sendiri, ketika jatuh ke sungai bisa ditolong oleh Tio Sing Sang dan kemudian sempat mendapat perawatan di rumah sakit dan nyawanya bisa terselamatkan. Setelah sehat, Lie Gouw Nio pun dinikahi oleh Tio Sing Sang dan mereka hidup bahagia.

Tokoh lain yang bisa dikategorikan sebagai tokoh yang tidak sadar diri adalah para dukun. Dalam "Busono" digambarkan seorang dukun bernama Mak Becot, yang merupakan langganan Siti Ningrum, nyainya dokter Solern. Mak Becot oleh Siti Ningrum dimintai tolong untuk memeriksa nasib Busono dan mengusahakan kenaikan gajinya. Sebagai dukun, Mak Becot menjalani saja apa yang diminta oleh pelanggannya itu. Hal itu tampak dalam dialog berikut.

- Tidak, mak, saya hanya mau iseng saja. Kebetulan tuan Dokter sedang bepergian, mengunjungi orang sakit di udik. Saya telah diberi ijin untuk berjalan-jalan mencari angin bersama saudara saya suami istri. Ini ipar misan saya Den Busono, ingin supaya gajinya lekas naik atau nasibnya biar lebih baik, sebab istrinya ini sudah tak sabar lagi, mendesak agar suaminya lekas-lekas pindah dan cari pekerjaan lain. Cobalah tolong periksa nasib dua orang suami istri ini.

- Aih, aih, ... ada-ada saja anak muda jaman sekarang! Kurang sabaran seperti dedemit.

Nyi dukun lalu mulai mengenakan kacamatanya, mengocok kartu yang diambilnya dari kotak kaleng bekas sigaret. Setelah selesai dikocok, ia minta agar Ningrum mencabut selembar buat Busono dan selembar buat istrinya, nyi janda jaksa, lalu selembar lagi untuk peringatan, nasib dan masa yang akan datang.

Ningrum mencabut kartu-kartu tersebut dengan airmuka bersungguhsungguh, sama sekali tak nampak main-main.

Setelah mengocok kartu sambil memperhatikan Ningrum sebentar nyi dukun lalu membeberkan kartunya baik-baik, kemudian diperhatikannya Busono dan nyi janda. Tiba-tiba dukun perempuan itu tertawa terbahak-bahak. Semua pun ikut tertawa. Sambil mencubit paha Ningrum nyi dukun berkata:

- Bisa, bisa, kenapa tidak bisa? Kalau sudah kawin juga bisa jadi taoke sendiri. Cuma Aden sekarang sedang jengkel sebab tidak terima gaji penuh. Tapi tak mengapa karena Aden tak di bawah perintah orang lain. (Soerjo dalam Tur, 1985: 380) 
Dalam cerita "Nyai Dasima" dukun hadir sebagai tokoh yang dimintai tolong oleh Samiun untuk bisa memberikan jampi-jampi yang bisa digunakan untuk memengaruhi Nyai Dasima agar mau meninggalkan suaminya dan mau diperistri oleh Samiun.

\section{Tokoh-Tokoh Cerita Pra-Indonesia se- bagai Representasi Identitas Keprain- donesiaan}

Seperti terurai di atas, tokoh-tokoh cerita pra-Indonesia terdiri atas tokoh yang sadar diri dan tokoh yang tidak sadar diri. Busono, tokoh intelektual yang berusaha memperjuangkan nilai-nilai kemanusiaan lewat pikiran-pikirannya, baik yang disampaikan secara lisan maupun lewat surat kabar tempatnya bekerja merupakan representasi dari kelompok intelektual pribumi. Tokoh Busono, yang menurut Ananta Toer (2003: 370) merupakan gambaran tentang diri Tirto Adi Soerjo (bersifat autobiografis) sebagai seorang pengarang pribumi, dengan mengacu pada teori strukturalisme genetik yang dikemukakan oleh Goldmann (1981), bisa disebut sebagai subjek kolektif atau subjek transindividual. Hal itu berarti bahwa Busono adalah wakil dari kelompok intelektual pada waktu itu yang sudah memiliki kesadaran berbangsa meskipun belum disebut apa nama bangsanya. Berdasarkan nama-nama tokoh dan kisah Ningrum (nyai) yang disejajarkan dengan selir raja Jawa, patut diduga bahwa bangsa dimaksud adalah bangsa Jawa.

Berbeda dengan Busono, Nji Paina, meskipun melakukan resistensi dengan menularkan cacar yang membawa Briot pada kematian, karena tindakannya itu lebih merupakan ekspresi dirinya sebagai individu yang terlanggar hak-haknya, lebih menggambarkan perannya sebagai subjek individual. Hal itu lebih diperkuat lagi dengan penggambaran penyakit yang menjadi penyebab matinya suami Nji Paina yang datangnya musiman yang lebih bersifat alamiah, ketimbang kultural. Demikian pula halnya dengan penyakit yang dijadikan sarana oleh Nji Paina untuk membunuh Briot yang datangnya juga musiman. Hal itu menunjukkan bahwa Nji Paina tidak berjarak dengan alam, merupakan bagian dari alam, yang berarti pula bisa dikategorikan sebagai subjek yang tidak sadar diri.

Albaram, sebagai orang yang masih keturunan keluarga Kerajaan Banten yang di masa lalu telah disamaratakan dengan tanah oleh Belanda, berusaha dengan berbagai cara untuk mendapatkan kekayaan lagi dengan berusaha menikahi Kong Hong Nio, yang mewarisi kekayaan Liem Tek Kan. Namun, usahanya itu mengalami kegagalan. Kegagalan itu lebih dikuatkan lagi dengan penggambaran dirinya yang dihukum gantung oleh Pemerintah Hindia Belanda di akhir cerita. Hal itu menunjukkan bahwa Albaram sebagai orang pribumi telah kalah melawan Belanda dan juga Cina.Hal ini menguatkan pandangan yang selama ini ada bahwa pada zaman kolonial Belanda orang-orang pribumi berada di bawah kekuasaan Belanda dan posisinya berada di bawah bangsa Cina.

Sebagai cerita yang sama-sama ditulis oleh H. Kommer, kisah Albaram dalam "Nyonya Kong Hong Nio" dan kisah Nji Paina dalam "Nji Paina" yang penggambaran hubungannya dengan kolonial Belanda sangat bertolak belakang, yang pertama, di akhir cerita digantung oleh Pemerintah Kolonial Belanda, sedangkan yang keduamembunuh Briot, satu bentuk perlawanan terhadap kesombongan orang Belanda, sungguh menimbulkan tanda tanya besar. Adakah H. Kommer sebagaipenulis Belanda dengan sengaja membuat cerita yang demikian? Ataukah ia hanya memerankan dirinya sebagai tukang cerita, hanya menuliskan kisah yang diketahuinya, tanpa ada keberpihakan yang jelas? 
Siti Ningrum yang dijadikan nyai oleh dokter Solern menggambarkan keadaan perempuan pribumi yang dikooptasi oleh orang Eropa. Ningrum memang dicukupi kebutuhan uang dan hartanya, tetapi, sebagaimana terjadi pada banyak nyai yang lain, hal itu dilakukan ketika Ningrum masih muda. Bila sudah tua, dengan gampang saja tuannya itu akan mengusirnya pergi. Lebih dari itu, Ningrum juga tidak punya anak dalam hubungannya dengan dokter Solern itu. Dengan keadaan serupa itu, bila dia diusir karena alasan sudah tua nanti, ia akan merasa dicampakkan begitu saja tanpa ada bekas yang tertinggal. Hal yang seperti itu bisa terjadi karena Ningrum tidak memiliki kesadaran diri yang bisa membangkitkan dirinya untuk bisa terbebas dari keterpurukan menjadi nyai yang hanya dijadikan objek pemuas tuannya. Siti Ningrum yang dijadikan nyai oleh dokter Solern dan Dasima oleh Edward menggambarkan keadaan perempuan pribumi yang dikooptasi oleh orang Eropa. Ningrum memang dicukupi kebutuhan uang dan hartanya, tetapi, sebagaimana terjadi pada banyak nyai yang lain, hal itu dilakukan ketika Ningrum masih muda. Bila sudah tua, dengan gampang saja tuannya itu akan mengusirnya pergi. Lebih dari itu, Ningrum juga tidak punya anak dalam hubungannya dengan dokter Solern itu. Dengan keadaan serupa itu, bila dia diusir karena alasan sudah tua nanti, ia akan merasa dicampakkan begitu saja tanpa ada bekas yang tertinggal. Hal yang seperti itu bisa terjadi karena Ningrum tidak memiliki kesadaran diri yang bisa membangkitkan dirinya untuk bisa terbebas dari keterpurukan menjadi nyai yang hanya dijadikan objek pemuas tuannya.

Sebagaimana Ningrum, Dasima juga dicukupi kebutuhan uang dan hartanya oleh tuannya. Namun, berbeda dengannya, Dasima memiliki anak dari Tuan Edward, dan bahkan kalau Dasima mau memeluk agama Protestan, Edward ber- niat menikahinya. Niatan Edward yang demikian menunjukkan bahwa Dasima akan diperlakukan sebagai orang yang mendapat tempat yang baik. Namun, keadaan Dasima yang serba tercukupi baik dari segi harta, uang, dan juga kebutuhan batin (perhatian dan anak), justru dibuat menjadi menderita oleh orang pribumi, Samiun. Sepertinya Samiun ingin membebaskan Dasima dari kekafiran, tetapi sesungguhnya di baliknya ada niatan tersembunyi, yaitu ingin mendapatkan kekayaan yang dimiliki Dasima. Logika Samiun ini sebenarnya konyol karena Dasima mendapatkan kekayaannya dari Edward tapi Samiun justru berusaha memisahkan Dasima dari Edward. Akibatnya, ketika harta dan uang Dasima sudah habis Samiun pun berusaha menyingkirkannya.

Penggambaran keadaan Siti Ningrum yang demikian tidak bisa dilepaskan dari hubungannya dengan pengarang, yaitu Tirto Adhi Soerjo, yang lewat pikiran dan tindakan Busono sebagai tokoh utama dalam cerita itu berusaha membebaskan Siti Ningrum dari ketertindasan dirinya sebagai nyai dokter Solern. Demikian pula halnya dengan penggambaran keadaan Dasima yang dicelakakan oleh Samiun yang pribumi, tidak bisa dilepaskan dari hubungannya dengan pengarangnya, G. Francis, yang adalah orang Belanda.

Tjonat, yang di usia tuanya dikenal oleh masyarakat luas sebagai perampok, sejak kecil memang sudah terbiasa melakukan kejahatan. Kejahatan itu ia lakukan bukan hanya terhadap orang pribumi, tetapi juga terhadap orang Cina dan Belanda. Berbagai kejahatan yang dilakukan oleh Tjonat, dalam cerita digambarkan sebagai aktivitas yang bersifat spontan, sebagai respon alamiah terhadap berbagai hal yang diinginkannya, tidak ada self reflection. Demikian pula halnya dengan tindakan yang dilakukan oleh Djojo dalam "Tjerita Rossina". Tindakan Tjonat maupun Djojo, dengan demikian, bukanlah 
tindakan dalam rangka memanusiakan dirinya, tetapi sebaliknya, menghancurkan kemanusiaannya sendiri. Penggambar-an serupa itu tidak bisa dilepaskan dari pengarangnya, F.D.J. Pangemanan.

\section{SIMPULAN}

Berdasarkan hasil dan pembahasan dapat disimpulkan hal-hal berikut. Pertama, dalam cerita pra-Indonesia tampak bahwa gambaran masyarakat pra-Indonesia itu sangat beragam. Ada tokoh intelek yang memiliki kesadaran yang tinggi tentang kebangsaan dan kemanusiaan seperti Busono; ada tokoh yang merasa harga dirinya terlanggar dan kemudian melakukan resistensi seperti Nji Paina; ada tokoh yang hak-hak previledgenya di masa lalu dihilangkan dan kemudian berusaha mendapatkannya lagi dengan melakukan tipu muslihat tetapi tidak berhasil seperti Albaram; ada tokoh yang hidupnya hanya semata mencukupi kebutuhan instingtifnya seperti Tjonat. Kedua, keberagaman karakter tokoh yang bisa diklasifikasikan menjadi tokoh yang sadar dan tak sadar diri tersebut, di dalam memandang persoalan identitas kepraindonesiaan tidak sepenuhnya berbanding lurus dengan kebangsaan pengarangnya. Dalam cerita "Busono" yang pengarangnya seorang pribumi, tokoh yang dihadirkan adalah tokoh yang sadar diri yang berusaha memperjuangkan nilai-nilai dalam rangka meningkatkan derajat dan harkat kemanusiaan dan kebangsaannya. Dalam cerita Nji Paina, meskipun pengarangnya adalah orang Belanda, dihadirkan tokoh yang resisten terhadap keburukan orang Belanda.

Meskipun tindakan yang mereka lakukan ada yang bersifat sadar diri dan ada yang tak sadar diri, sebagian yang mereka lakukan sesungguhnya merupakan tindakan antikolonial. Tindakan serupa itu ada yang memiliki hubungan berbanding lurus dengan kebangsaan pengarangnya, ada juga yang sebaliknya.

\section{UCAPAN TERIMA KASIH}

Karena artikel jurnal ini merupakan salah satu hasil eksplorasi dari kegiatan penelitian berjudul "Sastra Indonesia sebagai Sarana Pembentukan Identitas Nasional" yang dilaksanakan dengan bantuan dana dari LPPM UGM melalui skema Penelitian Unggulan Perguruan Tinggi, pertama-tama ucapan terimakasih disampaikan kepada pimpinan LPPM UGM beserta jajarannya. Ucapan terimakasih juga disampaikan kepada staf di KITLV Leiden Belanda yang dengan terbuka member kesempatan kepada peneliti untuk melakukan penelusuran literatur yang dibutuhkan. Juga kepada Dr. Ratna Saptari, ucapan terimakasih disampaikan atas segala bantuan yang diberikan selama kami berada di Belanda. Kepergian ke Belanda telah memberikan kepada kami frame dan landscape tentang Belanda yang bias membawa kami untuk sejenak mengimajinasikan kekuasaan Belanda di Hindia Belanda di masa pra-Indonesia.

\section{DAFTAR PUSTAKA}

Budianta, Melani. 2005. "Kolase Multikultural Sang Tukang Cerita Cerpen Indonesia 1870-an-1910-an", dalam Nona Koelit Koetjing: Antologi Cerita Pendek Indonesia Periode Awal (1870an-1910-an), Jakarta: Pusat Bahasa Departemen Pendidikan Nasional.

Dewanto, Nirwan. 1991. "Kebudayaan Indonesia: Pandangan 1991", Prisma, No. 10 Tahun XX.

Faruk. 2007. Belenggu Pasca-kolonial, Yogyakarta: Pustaka Pelajar.

Goldmann, Lucien. 1981. Method in the Sociology of Literature, England: Basil Blackwell Publisher.

Jenkins, Richard. 2008. Social Identity, third edition. London: Routledge.

Luxemburg, Jan van, Mieke Bal, Willem G. Weststeijn. 1989. Pengantar Ilmu Sastra, Jakarta: Gramedia 
Mahayana, Maman S. 2006. Bermain dengan Cerpen Apresiasi danKritikCerpen Indonesia. Jakarta: Gramedia Pustaka Utama.

Sarup, Madan. 2002. Identity, Culture and The Postmodern World, Edinburgh: Edinburgh University Press

Stanton, Robert. 1965. An Introduction to Fiction, New York: Holt, Rinehart and Winston.
Steger, Manfred B. 2005. Globalisme Bangkitnya Ideologi Pasar. Diterjemahkan dari Globalism, The New Market Ideo$\log y$, 2002, oleh Heru Prasetia, Yogyakarta: Lafadl Pustaka.

Toer, Pramoedya Ananta. 2003. Tempo Doeloe Antologi Sastra Pra-Indonesia. Jakarta Timur: Lentera Dipantara

Wahyudi, Ibnu. 2000. "Modern Literature of Indonesia", Modern Literature of Asean, Jakarta: Asean Committee On Culture and Information. 